Research Article

\title{
Optimized Ziegler-Nichols based PID Control Design for Tilt Suspensions
}

\author{
Fazilah Hassan, Argyrios C. Zolotas* and Tim Smith
}

\author{
School of Engineering, College of Science, University of Lincoln, Lincoln, LN6 7TS, United Kingdom
}

Received 2 March 2017; Accepted 11 October 2017

\begin{abstract}
PID control design using optimized modified Ziegler-Nichols tuning is for active suspensions of tilting nature is presented. The study of this refers to non-precedent tilt active suspensions for railway vehicles which comprises a cumbersome design trade-off. No study exists on detailed Ziegler-Nichols PID tuning for Single-Input-Single-Output type non-precedent tilt control. We therefore investigate such an approach, referred to here as simple3 tilt, emphasizing control performance that can be achieved in such type of tilting suspension problem. The aim is to provide a baseline design tool for control practicioners, in active suspensions of that nature, who may be more familiar with traditional PID tuning rules. Without loss of generality the suggestions in this paper can be considered in other applications of tilting suspension nature.
\end{abstract}

Keywords: active suspensions, Ziegler-Nichols, PID control, tilt suspensions, ride quality

\section{Introduction}

A number of applications involving some form of tilting action, or tilting mechanism or tilting suspensions exist. One of the most popular examples is high-speed tilting trains [1], other examples involve two and three-wheeled tilting vehicles [2]. Normally such tilting-related applications require active control and also to achieve a variety of design specifications (the design specifications may not necessarily be the same and can vary per nature of application, e.g. the details on exactly what tilting trains are expected to achieve vs what is required by a tilting road vehicle as an example). Albeit, in all cases of active tilt control, controller design and tuning can be a cumbersome design exercise (usually depending on complexity or simplicity of the design aims and also on controller structure and/or methodology).

In terms of simple control or initial control design, Proportional and Integral and Derivative (PID) controllers [3] are a popular classical type employed in a large number of industrial applications [3], [4], [5]. It is of no surprise that PID usually forms the simplest conventional controller for active tilt control applications. Numerous tuning methods have been (and are still) proposed by the worldwide control research community on PID control [3], still simple tuning rules are favored by -especially- the practising control engineers. It is noted that the use of advanced control design tools nowadays offer substantial benefits in the tuning of the PID controller in conjuction to simple tuning rules. In this paper, we present optimized PID control tuning for nonprecedent tilt of railway vehicles which is a tilting-nature control application comprising a cumbersome design tradeoff.

Tilting trains are used in high speed rail travel services in many countries around the world, essentially as a means of

\footnotetext{
*E-mail address: azolotas@lincoln.ac.uk

ISSN: 1791-2377 @ 2017 Eastern Macedonia and Thrace Institute of Technology. All rights reserved. doi:10.25103/iestr.105.02
}

reducing journey times without the need of building new rail infrastructure [1], [6], [7]. Their operational concept is simple, i.e. lean the vehicle body inwards on track corners to reduce lateral acceleration experienced by passengers hence allow train speed to increase. Active control is used to perform the tilting action and active tilting train systems is an area whereby control engineering has been a major contributor to modern train vehicle technology. High frequency curves on a railtrack sector is pertinent to increasing advantage of tilting train utilisation.

Early tilting train control attempted to compensate for the full passenger lateral acceleration on a curved-track, referred at the time as 'full nulling-tilt'. High motion sickness experienced by passengers shifted interest towards partial compensation of lateral acceleration on track corners [8], [9]. This became known as 'partial nulling-tilt' achieved by using a portion of the measured acceleration signal and a portion of the vehicle body roll angle (tilt). Control-wise the nulling-tilt method [10] of early tilting trains was intended to be simple and hence used feedback control from a lateral accelerometer mounted on the body of the current vehicle requiring tilt. At the time achieving sufficiently fast response on the curve transitions without causing ride quality degradation on straight track was difficult. The industrialnorm today uses acceleration information from a non-tilting part of the preview vehicle to provide the required tilting angle, with a straightforward tilt angle feedback controller locally to enable vehicle roll to the indicated tilt [8], [9]. This scheme is called "tilt with precedence" [9] [10], and typical tilt action profiles employ $60-70 \%$ compensation.

However, "Nulling-tilt" or 'non-precedent tilt' still forms an important research problem mainly due to the simplicity and straighforward failure detection it offers compared to "tilt with precedence".

Some papers that address a variety of control methods and approaches both on non-precedent and precedent tilt approaches can be found in the literature [9], [10], [11]. The paper by Zamzuri-et-al [12] employed ITAE and Ziegles- 
Nichols fuzzy PID-tilt, while earlier work by Pearson-et-al [10] looked at both classical and optimal control from a practical viewpoint of limited tilt for an anti-roll bar tilt vehicle. Multivariable control for the tilt problem directly dealing with the complexity of the tilt control design is discussed here [13], [14], [15]. Recent work presented in [16], [17] discussed optimized PID control and refined PIDbased loop-shaping with non-rational filters for nonprecedent tilt respectively.

From a PID control tuning point of view, the simplest method remains the Ziegler-Nichols technique [3], [18] and normally each newly proposed tuning method almost always include comparison with Ziegler-Nichols. In this context, Zieglers-Nichols modified approach has been discussed in the control literature both from an analytical point of view i.e. to provide a more optimized design for process control problems- [19] and on applications other than the railway tilt control one, i.e. such as in fractional PI control [20].

It is worth noting that although work on PID control for tilting vehicles can be found in the control literature, no particular study exists on detailed Ziegler-Nichols PID tuning for non-precedent rail vehicle tilt. We therefore investigate the effect of such an approach, in fact the Ziegler-Nichols modified rule [3] on tilt control performance and some related robustness aspects. We refer to the approach presented in this paper as 'simple ${ }^{3} t i l t$ ', i.e. a simple tuning method, for a simple classical controller, applied to a simple tilt control setup.

\section{Vehicle model for control design purposes}

Information about the model used for design purposes in this paper are presented here. The endview model of a railway vehicle suffices, and is shown on Fig.1. The endview model, essentially being a "suspension-constrained pendulum" comprises the (strongly) coupled modes of interest, i.e. lateral and roll motion. The dynamic model is of 4 Degrees of Freedom nature (with additional states characterising airspring contribution, wheelset kinematics and actuator servo). Wheelsets do not play a particular role for tilt control and hence only the filtering characteristic for lateral track irregularities is considered.

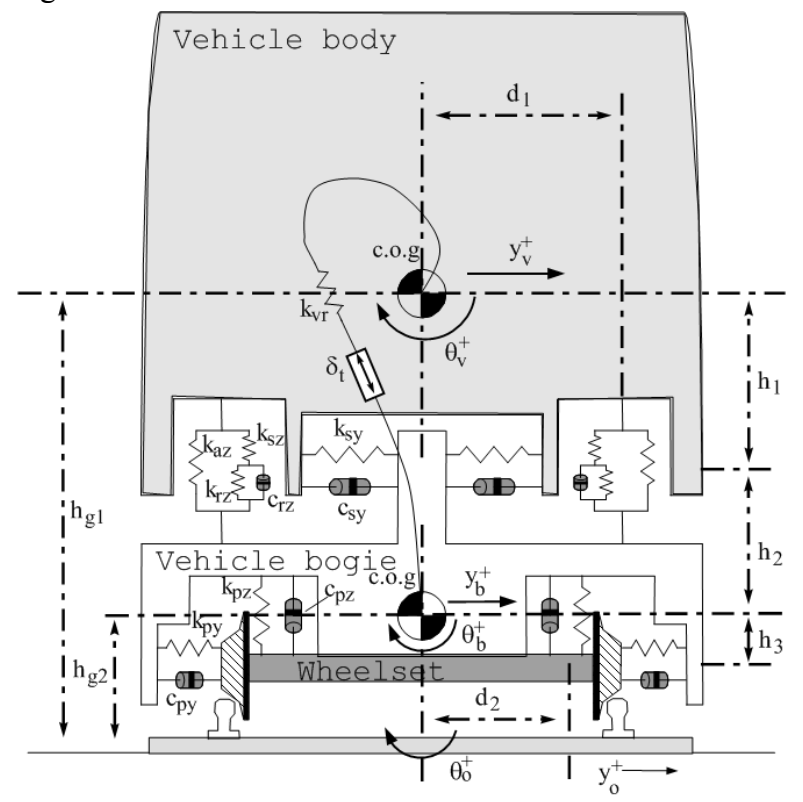

Fig. 1. Tilting vehicle end-view
In this paper we utilise only the design model transfer function of interest used for the PID-based non-precedent tilt. The actual details of the model, as well as of the track inputs exciting the vehicle, can be found in [15]. Note that The tilt mechanism used is that of an Active anti-roll bar (ARB) which provides tilt action across the secondary suspension (the only assumption here is that the mechanism will provide the full necessary tilt action for $60 \%$ acceleration compensation on steady-state corner). The linearised endview model version on curved track suffices (due to the small angle on the curved rail track). In this paper, the design transfer function of interest is the dynamic relationship between effective cant deficiency $Y_{\text {e.c.d }}$ and the control input $\Delta_{t-i d e a l}$ given in (1). The control input is the ideal tilt $\delta_{t_{i}}$ (this is processed via the servo-type actuator representation in the model). The vehicle is travelling on a rail track which essentially provides the input vector of track exogenous inputs, i.e. curvature, cant, and lateral track irregularities excitation. The modal analysis is presented in Table 1 (most important modes given in bold font).

Table 1. Modal analysis for the ARB model

\begin{tabular}{l|l|l}
\hline Mode & Damping & Frequency \\
\hline Body lower sway & $\mathbf{1 6 . 5 \%}$ & $\mathbf{0 . 6 7 H z}$ \\
Body upper sway & $\mathbf{2 7 . 2 \%}$ & $\mathbf{1 . 5 0 H z}$ \\
Bogie lateral & $\mathbf{1 2 . 4 \%}$ & $\mathbf{2 6 . 8 H z}$ \\
Bogie roll & $\mathbf{2 0 . 8 \%}$ & $\mathbf{1 1 . 1 H z}$ \\
Bogie lateral kinematics & $20.0 \%$ & $5.00 \mathrm{~Hz}$ \\
Air spring & $100.0 \%$ & $3.70 \mathrm{~Hz}$ \\
Actuator & $50.0 \%$ & $3.50 \mathrm{~Hz}$ \\
\hline
\end{tabular}

\section{The design framework}

The design framework employed here can be seen in Fig. 2. This illustrates the early tilting train control approach that attempted to compensate for passenger lateral acceleration on curved-track using local vehicle sensor innformation. It is essentially of SISO (single input single output) control nature (if the feedback is considered to be the effective cant deficiency). Note that zero effective cant deficiency on steady curve maps to $60 \%$ passenger acceleration compensation. The transfer function suffers from NonMinimum Phase (NMP) zeros, i.e. unstable zeros that impose performance constraints.

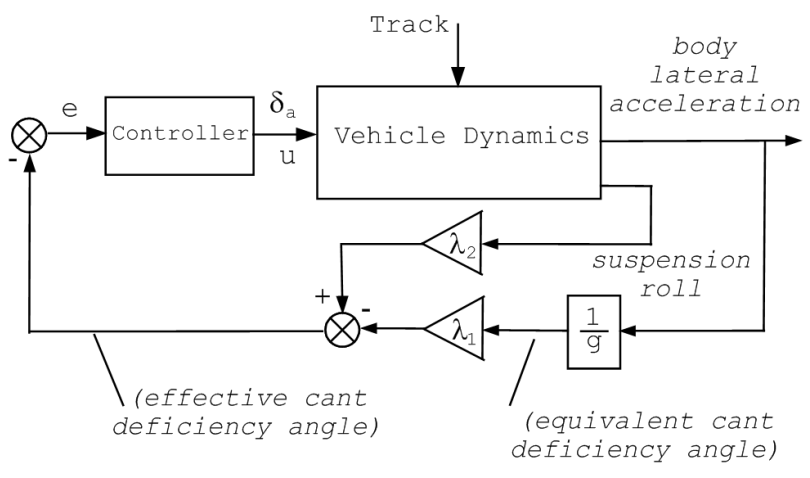

Fig. 2. Non-precedent tilt feedback control

The pole-zero map of the uncompensated Open-Loop system is shown in Fig. 3, with the two NMP zeros on the right hand of the s-plane. The more conservative zero is the slow (closer to the origin from the right). Regarding speed of 
response, the NMP zeros limit the bandwidth of the system typically to less than half of the slower NMP zero frequency
[16]. The controller block represents a PID controller, with the transfer function given in (2).

$$
\frac{Y_{e . c . d}(s)}{\Delta_{t_{i}}(s)} \frac{27.5 e 3(s+26.2)(s+40.7)(s-29.4)(s-6)\left(s^{2}+7.65 s+24.4\right)\left(s^{2}+4.8 s+15.8 e 3\right)}{(s+23.2)\left(s^{2}+1.4 s+17.4\right)\left(s^{2}+5.1 s+88\right)\left(s^{2}+22 s+483.6\right)\left(s^{2}+29.2 s+4.8 e 3\right)}
$$

\section{PID control design.}

PID is considered a simple robust classical controller, and the area with most practical examples of PID control is that of Process Control (typified in the checmical, pharamaceutical and petrochemical industries). Not surprisingly PID is also the simplest robust controller choice for tilting suspension control, as it offers both integral action to force the required amount of acceleration reduction on steady-curve, and the necessary proportional/derivative actions to limit phase lag at high frequencies (compared to the system bandwidth that is). We investigate the effect of such an approach emphasizing tilt control performance

The usual PID controller expression with derivative cutoff is used here (see Equation 1). The derivative cut-off is up to about $20 \mathrm{~Hz}$ (well above the frequency range of interest for the tilt control application, although in other papers a higher cut-off was employed to maintain a more "ideal" PID controller structure).

$K_{\widetilde{P I D}}=k_{p}\left(1+\frac{1}{\tau_{1} s}+\frac{\tau_{2} s}{\frac{S}{N}+1}\right)$

With parameters $k_{p}$ the proportional gain, $\tau_{l}$ the integral time constant and $\tau_{2}$ the derivative time constant.

The PID controller here is designed to: (i) maintain straight track (stochastic) ride quality [21] degradation performance no more than 7.5\% [9], [22] (we assess the weighted lateral acceleration signal [15])(ii) to minimize $\mathrm{P}_{\mathrm{CT}}$ (standing) factor ${ }^{I}$ which addresses the level of passenger comfort on curve transitions (deterministic/ tilt following). Note that due to the NMP zeros in the plant TF naturally the bandwidth of the system, with a linear controller, will be limited and well below half the frequency of the slow nonminimum phase zero, i.e. much less than approx. $3 \mathrm{rad} / \mathrm{s}$ in the case here. Essentially we follow the assessment proposed in [23], also seen in other tilt related papers [14], [15], [16]. More explanation on $\mathrm{P}_{\mathrm{CT}}$ factor can be found in Appendix B. The full assessment approach for tilt control can found in [23]. From a control theoretic point of view one could refer to the $\mathrm{P}_{\mathrm{CT}}$ factor as more advanced version of an IAE metric, or a more "rail tilt suspension" linked metric.

\subsection{Frequency-reponse Ziegler-Nichols.}

The Ziegler-Nichols method is still a rather popular choice in PID design (and as mentioned previously in the paper is a basis for comparison for other tuning techniques). We employ the $Z-N$ frequency response method, which is based on the knowledge of the point of the system's Nyquist curve that intersects the negative real axis. In fact, this point of intersection is called "ultimate point" as it refers to the ultimate gain and ultimate period. In particular, $k_{u}$ (the ultimate gain) is the proportional gain before system

${ }^{1}$ Ideally the fundamental tilting response, as measured by the PCT factor, must be as good as a passive vehicle at lower (non-tilting) speed [23]. However, due to the delay in the non-precedent tilt approach and the dynamic interactions from the suspensions we are investigating what level can be achieved by the simple controller. instability and $T_{u}$ (the ultimate period) is the critical period at inverse of frequency of -180deg.

For completeness, Table 2 refers to a set of recommended gain parameters to achieve a decay ratio of $1 / 4$ - Note that Ziegler-Nichols originally made the recommendations, based on an extensive set of simulations on diferent processes, mainly to achieve good load disturbance performance. Their systems were ones typified in the process control industry [3].

Table 2. Ziegler-Nichols controller gains (freq. resp. method)

\begin{tabular}{l|l|c|c}
\hline Controller type & \multicolumn{1}{|c|}{$\boldsymbol{k}_{\boldsymbol{p}}$} & $\boldsymbol{\tau}_{\mathbf{1}}$ & $\boldsymbol{\tau}_{\mathbf{2}}$ \\
\hline $\mathbf{P}$ & $\mathbf{0 . 5} k_{u}$ & & \\
$\mathbf{P}+\mathbf{I}$ & $\mathbf{0 . 4} k_{u}$ & $\mathbf{0 . 8} P_{u}$ & \\
$\mathbf{P}+\mathbf{I}+\mathbf{D}$ & $\mathbf{0 . 6} k_{u}$ & $\mathbf{0 . 5} P_{u}$ & $\mathbf{0 . 1 2 5} P_{u}$ \\
\hline
\end{tabular}

$\mathrm{P}_{\mathrm{u}}$ : ultimate period, $\mathrm{k}_{\mathrm{u}}$ : ultimate gain

Normally Z-N tuning produces closed-loop systems with insufficient damping, hence re-tuning is a necessity. A wellknown modified tuning approach is based on the graphical intererpetation of the frequency response method, i.e. design a controller to move any arbitrary point of the frequency response curve (e.g. Nichols curve etc.) to a suitable location. If the "arbitrary point" is the "ultimate point", as mentioned before, it is known as Modified $Z-N(\mathrm{M} / \mathrm{Z}-\mathrm{N})$ method [3].

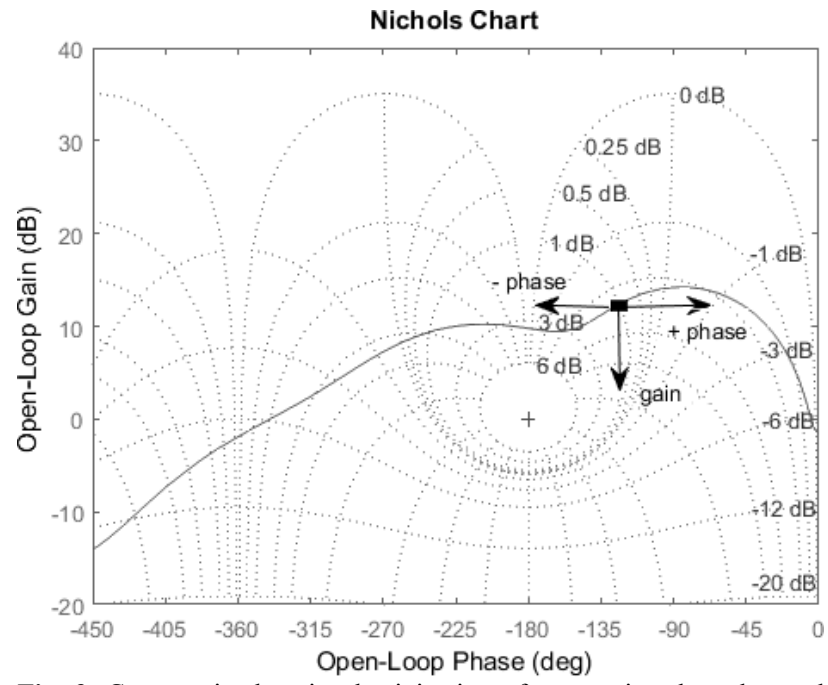

Fig. 3. Curve point location by injection of pure gain, phase lag and phase lead.

The limitation of the method is that it relocates on point and performance will depend on the nature of the overall compensated curve, its slope etc., albeit is a very simple method of tuning in its manual form. The modified Z-N method is followed in this paper.

The derivation of the M/Z-N tuning parameter equations for a PID controller are actually given in [3], hence we only list the resulting equations for moving the ultimate point on the frequency response: 
$\left\{\begin{array}{c}k_{p}=k_{u} r_{b} \cos \varphi_{b} \\ \tau_{1}=\frac{P_{u} \tan \varphi_{b}}{4 \alpha \pi}\left(1+\sqrt{\frac{4 \alpha}{\tan ^{2} \varphi_{b}}+1}\right) \\ \tau_{2}=\alpha \tau_{1}\end{array}\right.$

Where, $\alpha$ is the ratio of derivative time constant to integral time constant for the PID controller, $r_{b}$ the gain to introduce by the controller at the given point, $\varphi_{b}$ is the phase to introduce by the controller at the given point. In the common $\mathrm{Z}-\mathrm{N}$ rule $\alpha$ is set to $1 / 4$ but this is not the case in this paper. It is worth noting that for the tilt system with the nominal values given here, the ultimate gain is $k_{u}=0.325$ and period is $P_{u}=0.825 \mathrm{sec}$.

\subsection{Optimized Z-N modified tuning}

The manual tuning analysis reveals trends of parameter variation in the Z-N modified approach, see (3), their mapping into PID gains and impact on tilt performance. We utilise an optimization framework to improve tuning of the PID controller given the cumbersome performance trade-off and the non-minimum phase characteristics of the design plant.

In most time domain optimization based PID works four typical and widely popular performance indices for PID design in the time domain appear [3], [18], [19], [20]. Namely the ISE (integral of squared error), IAE (integral of absolute error), ITSE (integral of time multiply squared error) and ITAE (Integral time of absolute error). However, as seen in [16] these indeces may be of limited use to the tilt control problem when it comes to performance and robustness properties. In this paper we focus on minimization given by (4).

Note that "rqd" refers to the ride quality [16] degradation of the tilting system compared to the non-tilting system at the higher speed $(58 \mathrm{~m} / \mathrm{s}$ i.e. $30 \%$ higher than the non-tilting speed). The sensitivity peak bound imposez a basic level of robustness (note that we do not consider a core robust control scheme explicitly in this paper). Normally for the sensitivity peak a bound of no more than 2 is used [24] but as the system is non-minimum phase and a very simple controller is employed, a slightly higher bound is allowed. $R_{+}$is the set of positive real numbers.

Choice of initial conditions: The optimization process commences with parameter conditions for the optimization process, especially for the practising control engineer, that stem from the original suggestion in [0], i.e. $r_{b}{ }^{0}=$ $0.5, \varphi_{b}{ }^{0}=20 \mathrm{deg}, \alpha^{0}=0.25$.

Different initial conditions will impact the nonlinear optimization outcome due to the existence of local minima. A way to prevent the optimisation process getting stuck in local minimum is to add more iterations. We utilise multistart to perturbing initial conditions in the optimization procedure (about 10 iterations with a random initial value generation in the interval $[0.25 \bar{x}, 5 \bar{x}]$, where $\bar{x}$ is the row vector of initial parameters $\left(r_{b}^{0}, \varphi_{b}{ }^{0}, \alpha^{0}\right.$, as discussed above). Note that unrealistic parameter bounds for the initial conditions would normally result to unrealistic optimization. The problem can be implemented in Matlab software using either fminsearch(), with appropriate violation constraints, or fminbid() functions.

\section{Results and Discussion}

The section begins by analysing the results on the nominal system, then extends discussion to preliminary assessment of performance under parametric perturbations from a robustness point of view of the proposed controller solutions.

\subsection{Nominal performance}

Firstly, the design follows a manual approach i.e. manually changing the $\mathrm{M} / \mathrm{Z}-\mathrm{N}$ parameters and investigating the trend of responses of the Closed-loop system. The parameter values start from the recommended ones as discussed previously, i.e. $\left(r_{b}=0.5, \varphi_{b}=20 \mathrm{deg}, \alpha=0.25\right.$ (which is a rather process-control based recommendation) and proceeds by varying (mainly the ratio $\alpha$ and the phase $\varphi_{b}$ ). The parameter variation trend (manually) is shown in rows 2 (original) -6 (case 4) of Table 3 .

The results are shown in Figures 4-9. Note that the topleft subfigure shows the effective cant definiciency response (if it is zero then the required amount of tilt on steady-curve is achieved).

Table 3. Modified Z-N parameter values

\begin{tabular}{c|c|c|c}
\hline Z-N modified & $\alpha$ & $r_{b}$ & $\varphi_{b}(\mathrm{deg})$ \\
\hline original & 0.25 & 0.5 & 20 \\
case 1 & 0.5 & 0.5 & 20 \\
case 2 & 0.7 & 0.5 & 20 \\
case 3 & 0.9 & 0.5 & 20 \\
case 4 & 0.9 & 0.4 & 10 \\
case 5 (opt) & 4.69 & 0.293 & 41.1 \\
\hline
\end{tabular}

$$
\begin{array}{cc}
\min _{r_{b}, \varphi_{b}, \alpha \in R_{+}}\left[(2.80 \ddot{y}+2.03 \dddot{y}-11.1)_{\geq 0}+0.185 \dot{\theta}^{2.283}\right] \\
\text { s.t. } \\
\\
\\
\quad\left\|S\left(\mathrm{r}_{\mathrm{b}}, \varphi_{\mathrm{b}}, \alpha\right)(j \omega)\right\|_{\infty} \leq 2.4
\end{array}
$$

The dotted line presents the same response if a pseudoreference E.C.D step input of unity amplitude was applied (with all railtrack inputs set to zero). Increasing $\alpha$ makes the response more aggressive for the effective cant deficiency and degrades ride quality level. Decreasing the phase $\varphi_{b}$ contribution also complements aggresiveness of response due to the move of the curve closer to the Nichols plot point (0 dB, -180deg).

The last row of Table 3 presents the results from the optimization process. The value of ratio $\alpha$ and that of the phase $\varphi_{b}$ are substantially increased relative to the original recommended values, while the value of the gain $r_{b}$ decreased. The optimization process essentially aims to satisfy the required constraints and the PCT minimization by moving one point on the Nichols plot. The results are shown on Figure 10.

For completeness the obtained PID controller transfer functions are shown on Table 4. Figures 11 and 12 present the PID controllers magnitude response and control sensitivity plot respectively. Note that the control action (as seen from the magnitude level in the control sensitivity plot) is constrained and not exceeding $10 \mathrm{~dB}$ at high frequencies.

The details of the designs in terms of using the aforementioned assessment approach are shown on Table 5. This also illustrates the benefits of using the optimization approach. 

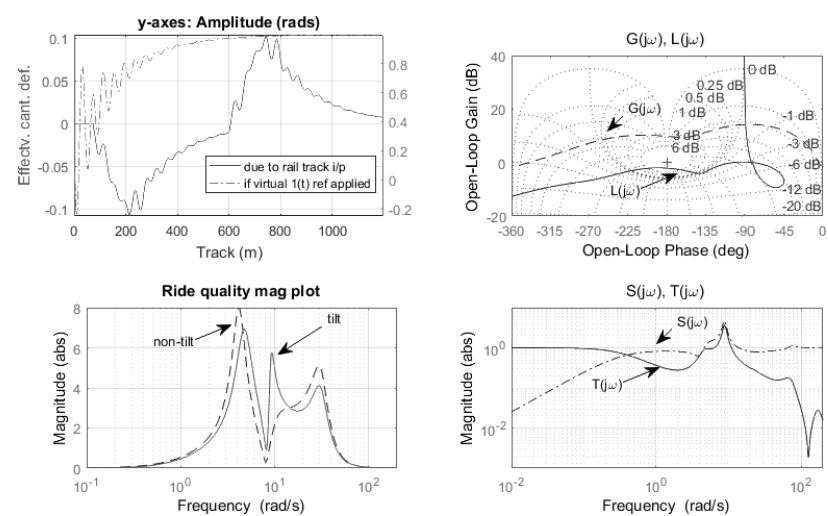

Fig. 4. Ziegler-Nichols freq. resp. (ultimate gain/phase)
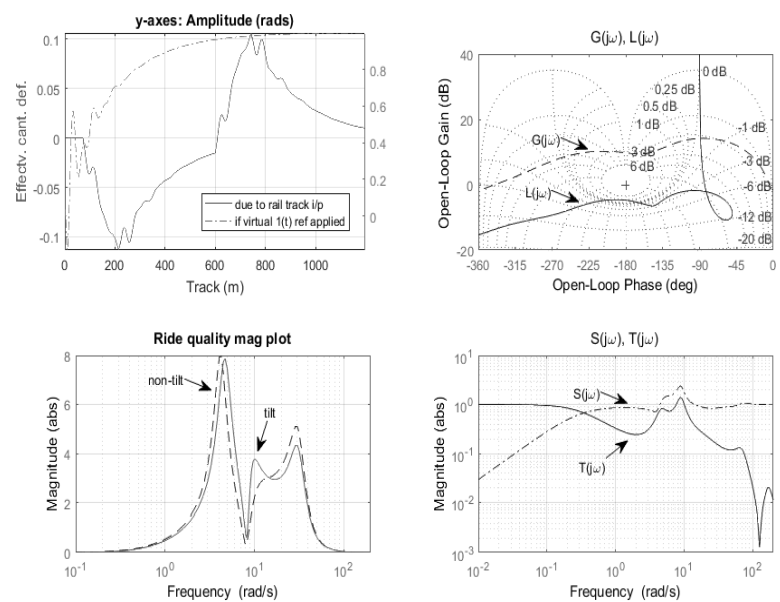

Fig. 5. Modified Ziegler- Nichols (original)
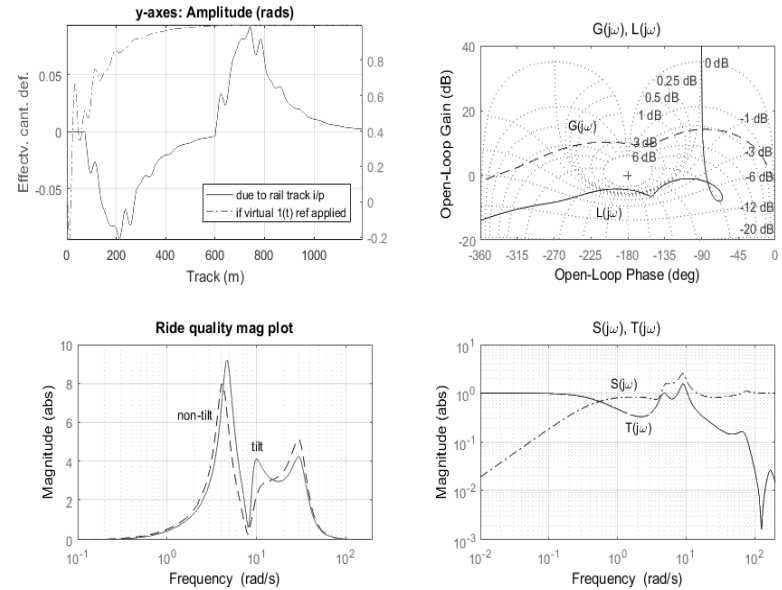

Fig.6. Modified Ziegler- Nichols (case 1)
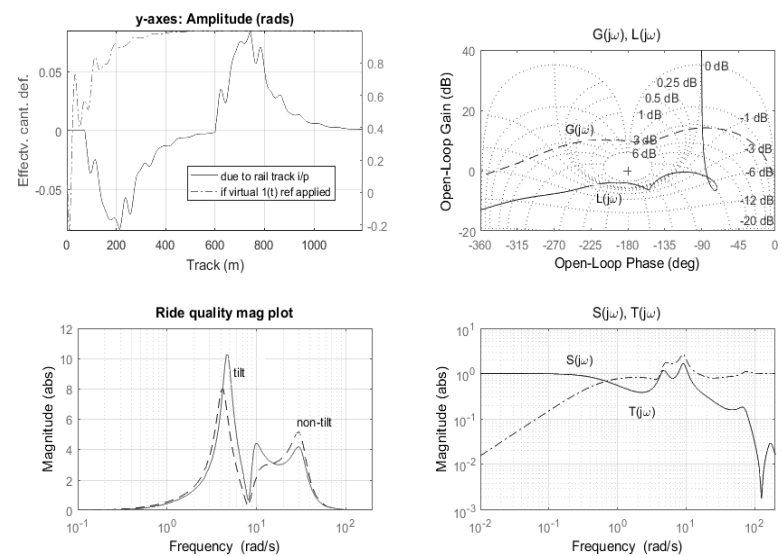

Fig.7. Modified Ziegler- Nichols (case 2)
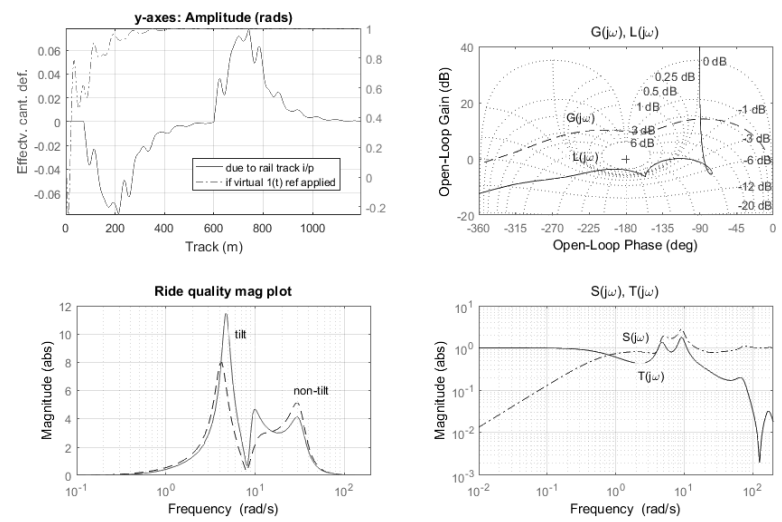

Fig. 8. Modified Ziegler- Nichols (case 3)
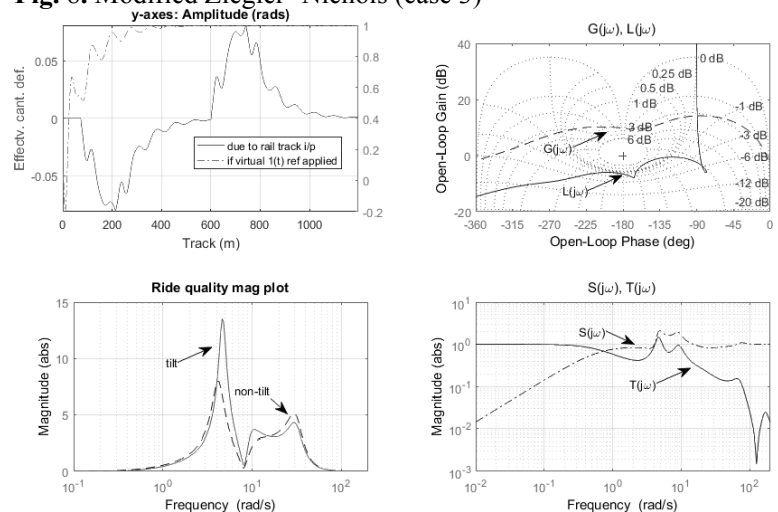

Fig.9. Modified Ziegler- Nichols (case 4)
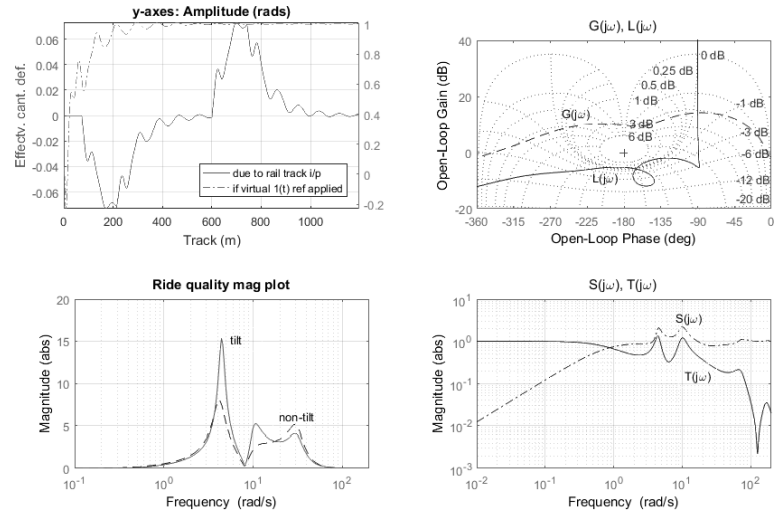

Fig.10. Modified Ziegler- Nichols (case 5, opt)

The achieved level is close to the expected results for such optimized PID controller type as also shown in [16]. For completeness, the stability margins for all controllers (nominal plant) are presented on Table 6.

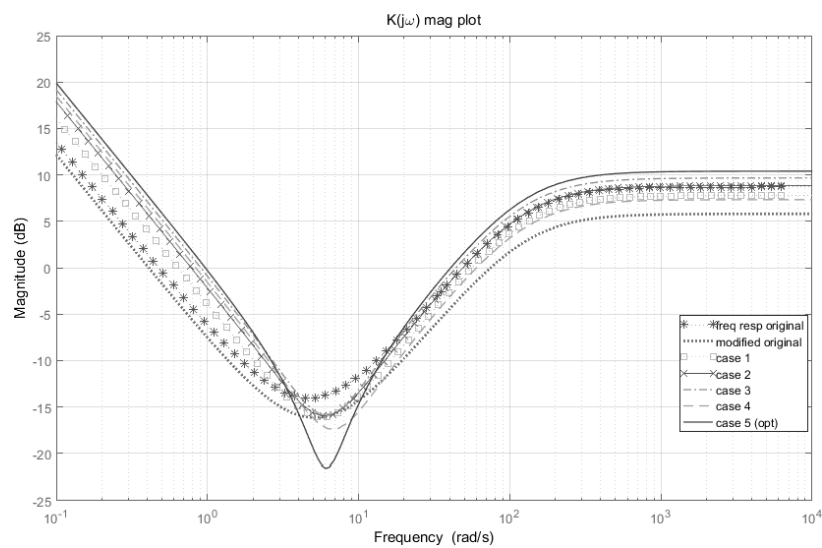

Fig.11. PID Controller magnitude frequency response (integral action below $0.1 \mathrm{rad} / \mathrm{s}$ not shown here) 


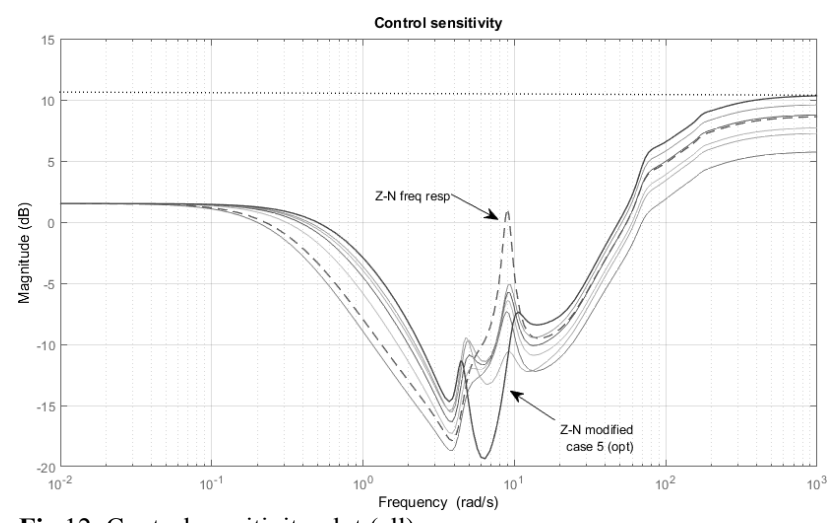

Fig.12. Control sensitivity plot (all)

\subsection{Robustness considerations}

Here a brief discussion on robust performance considerations for the optimized design is presented. We consider a $+/-20 \%$ uncertainty (from nominal values, see Appendix A) on each of the following parameters of the model: vehicle body mass and inertia, lateral suspension stiffness and damping, airspring suspension stiffnesses and damping, roll-bar stiffness. The considered uncertainty produces a family of 25 plants (in fact for some of the low extreme suspension parameter values, the vehicle would normally undergo maintenance service in practice). The analysis is based on Monte Carlo approach, and uses the controller of case 5 .

Table 4. PID controllers list

\begin{tabular}{|c|c|c|c|}
\hline Design & $K_{P I D}$ controller & Design & $K_{P I D}$ controller \\
\hline Z-N PID freq & $1.123 s^{2}+10.3 s+24.47$ & Z-N modified & $0.5392 s^{2}+3.887 s+19.16$ \\
\hline resp Original & $\frac{0.4129 s^{2}+51.88 s}{07321 s^{2}+7344 s+1916}$ & $\begin{array}{l}\text { case } 2 \\
7-N \text { modified }\end{array}$ & $\begin{array}{c}0.1949 s^{2}+24.49 s \\
051 s^{2}+334 s+19\end{array}$ \\
\hline Z-N modified & $0.7321 s^{2}+7.344 s+19.16$ & Z-N modified & $0.51 s^{2}+3.364 s+19.16$ \\
\hline $\begin{array}{l}\text { original } \\
\text { Z-N modified }\end{array}$ & $\begin{array}{c}0.3754 s^{2}+47.17 s \\
0.5871 s^{2}+4.745 s+19.16\end{array}$ & $\begin{array}{l}\text { case } 3 \\
\text { Z-N modified }\end{array}$ & $\begin{array}{c}0.1676 s^{2}+21.06 s \\
0.3534 s^{2}+2.569 s+16.06\end{array}$ \\
\hline case 1 & $0.2397 s^{2}+30.13 s$ & $\begin{array}{l}\text { case } 4 \\
\text { Z-N modified } \\
\text { case } 5 \text { (optim.) }\end{array}$ & $\begin{array}{c}0.152 s^{2}+19.1 s \\
0.2372 s^{2}+0.739 s+9.0 \\
0.0741 s^{2}+9.316 s\end{array}$ \\
\hline
\end{tabular}

Table 5 PID controller performance assessment with the different design approaches

\begin{tabular}{|c|c|c|c|c|c|c|c|c|}
\hline \multicolumn{2}{|c|}{$\begin{array}{c}\text { Deterministic } \\
\text { (as per given units) }\end{array}$} & \multirow{2}{*}{$\begin{array}{c}\text { Z-N PID } \\
\text { freq resp } \\
\text { Original } \\
6.23 \\
20.923 \\
\end{array}$} & \multirow{2}{*}{$\begin{array}{c}\begin{array}{c}\text { Z-N PID } \\
\text { modified } \\
\text { original }\end{array} \\
6.804 \\
21.024\end{array}$} & \multirow{2}{*}{$\begin{array}{c}\begin{array}{c}\text { Z-N PID } \\
\text { modified } \\
\text { case 1 }\end{array} \\
5.278 \\
19.130 \\
\end{array}$} & \multirow{2}{*}{$\begin{array}{c}\begin{array}{c}\text { Z-N PID } \\
\text { modified } \\
\text { case 2 }\end{array} \\
4.624 \\
18.160\end{array}$} & \multirow{2}{*}{$\begin{array}{c}\begin{array}{c}\text { Z-N PID } \\
\text { modified } \\
\text { case 3 }\end{array} \\
4.182 \\
17.432 \\
\end{array}$} & \multirow{2}{*}{$\begin{array}{c}\begin{array}{c}\text { Z-N PID } \\
\text { modified } \\
\text { case } 4\end{array} \\
4.427 \\
17.580 \\
\end{array}$} & \multirow{2}{*}{$\begin{array}{c}\begin{array}{c}\text { Z-N PID } \\
\text { modified } \\
\text { case 5 (opt) }\end{array} \\
4.07 \\
16.68 \\
\end{array}$} \\
\hline $\begin{array}{c}\text { Lateral } \\
\text { acceleration }\end{array}$ & $\begin{array}{c}\text { RMS deviation }(\% \mathrm{~g}) \\
\text { Peak value }(\% \mathrm{~g})\end{array}$ & & & & & & & \\
\hline $\begin{array}{c}\text { Roll } \\
\text { gyroscope }\end{array}$ & $\begin{array}{c}\text { RMS deviation } \\
(\mathrm{rad} / \mathrm{s}) \\
\text { Peak Value }(\mathrm{rad} / \mathrm{s})\end{array}$ & $\begin{array}{l}0.034 \\
0.080\end{array}$ & $\begin{array}{l}0.034 \\
0.072 \\
\end{array}$ & $\begin{array}{l}0.032 \\
0.081 \\
\end{array}$ & $\begin{array}{l}0.030 \\
0.087 \\
\end{array}$ & $\begin{array}{l}0.029 \\
0.092 \\
\end{array}$ & $\begin{array}{l}0.030 \\
0.089 \\
\end{array}$ & $\begin{array}{l}0.029 \\
0.091 \\
\end{array}$ \\
\hline $\begin{array}{l}\mathrm{P}_{\mathrm{CT}} \\
\text { related }\end{array}$ & $\begin{array}{c}\text { Peak jerk level } \\
(\% \mathrm{~g} / \mathrm{s}) \\
\text { Standing }(\% \text { of } \\
\text { passeng.) } \\
\text { Seated }(\% \text { of } \\
\text { passeng.) }\end{array}$ & $\begin{array}{r}11.646 \\
77.15 \\
25.013\end{array}$ & $\begin{array}{c}11.16 \\
75.208 \\
24.423\end{array}$ & $\begin{array}{l}10.469 \\
69.896 \\
22.343\end{array}$ & $\begin{array}{l}10.134 \\
67.627 \\
21.356\end{array}$ & $\begin{array}{r}9.905 \\
66.077 \\
20.648\end{array}$ & $\begin{array}{r}9.739 \\
65.553 \\
20.527\end{array}$ & $\begin{array}{r}9.247 \\
62.465 \\
19.334\end{array}$ \\
\hline $\begin{array}{l}\text { Ride quality } \\
\text { (passenger } \\
\text { comfort) }\end{array}$ & $\begin{array}{c}\text { Tilting train } \\
\text { Degradation. }(\%)\end{array}$ & $\begin{array}{l}2.664 \\
-6.47\end{array}$ & $\begin{array}{r}2.696 \\
-5.347\end{array}$ & $\begin{array}{c}2.758 \\
-3.166\end{array}$ & $\begin{array}{c}2.813 \\
-1.229\end{array}$ & $\begin{array}{l}2.874 \\
0.915\end{array}$ & $\begin{array}{l}2.969 \\
4.246\end{array}$ & $\begin{array}{c}3.062 \\
7.5\end{array}$ \\
\hline
\end{tabular}

Table 6. Stability margins for the controllers

\begin{tabular}{|c|c|c|c|c|c|}
\hline Design approach & $\begin{array}{c}\text { GM } \\
\text { (linear) }\end{array}$ & $\begin{array}{c}\text { PM } \\
\text { (deg) }\end{array}$ & $\begin{array}{c}\text { GM cross-over } \\
(\mathrm{rad} / \mathrm{s})\end{array}$ & $\begin{array}{c}\text { PM cross-over } \\
(\mathrm{rad} / \mathrm{s})\end{array}$ & $\begin{array}{c}\|S(j \omega)\|_{\infty} \\
\text { (linear) }\end{array}$ \\
\hline$Z-N$ freq resp & 1.27 & 77.16 & 8.89 & 4.396 & 4.665 \\
\hline $\begin{array}{c}Z-N \text { modified } \\
\text { original }\end{array}$ & 1.72 & 96.3 & 8.68 & 0.3462 & 2.38 \\
\hline $\begin{array}{c}Z-N \text { modified } \\
\text { case } 1\end{array}$ & 1.66 & 95.75 & 8.78 & 0.548 & 2.53 \\
\hline $\begin{array}{c}Z-N \text { modified } \\
\text { case } 2\end{array}$ & 1.62 & 95.42 & 8.85 & 0.68 & 2.65 \\
\hline $\begin{array}{l}Z-N \text { modified } \\
\text { case } 3\end{array}$ & 1.58 & 57.29 & 8.9 & 4.25 & 2.77 \\
\hline $\begin{array}{c}Z-N \text { modified } \\
\text { case } 4\end{array}$ & 2.13 & 94.0 & 8.42 & 0.74 & 2.13 \\
\hline $\begin{array}{l}Z-N \text { modified } \\
\text { case } 5 \text { (opt) }\end{array}$ & 1.91 & 90.86 & 9.97 & 0.851 & 2.1 \\
\hline
\end{tabular}

It can be seen from Figures 13, 14 and 15 that the designed system with the optimization-based PID controller maintains stability for the level of dynamic uncertainty considered above (some oscillations noted for 2 plants, are due to the extreme parameter combinations). Regarding ride quality, some of the uncertain parameter combinations result to degraded performance $>7.5 \%$ degraded. 
In particular, and given the plant family of the 25 plants (one being the nominal on which the design was performed), 17 out of 25 cases maintain ride quality less than $7.5 \%$ worst while the remaining 8 combinations violate the ride quality criterion. The worst case ride quality is about $68 \%$ degraded and relates to the uncertain case of a heavier mass on suspension with lesser damping than the nominal value. This is not unexpected as only a light robustness touch was included in the design process. Still, considering that only the constrain on peak sensitivity value was imposing a level of basic robustness and using such a very simple tuning approach, the result can be regarded as highly satisfactory for such a controller.

The interested reader is referred to detailed robustness investigation for other types of PID controllers in [16].

\section{Conclusions}

We presented a detailed study of Ziegler-Nichols based PID control design for non-precedent tilt vehicle platform. Design simplicity was emphasized and the related impact on deterministic/stochastic tilt performance was investigated. Optimized tuning of the modified Ziegler-Nichols parameters has substantial impact on performance improvement (regardless the design plant's non-minimum phase zeros). This is achieved by use of nonlinear optimization to address the conflicting performance specifications. Detailed performance results on the nominal models as well as initial robustness results are presented.

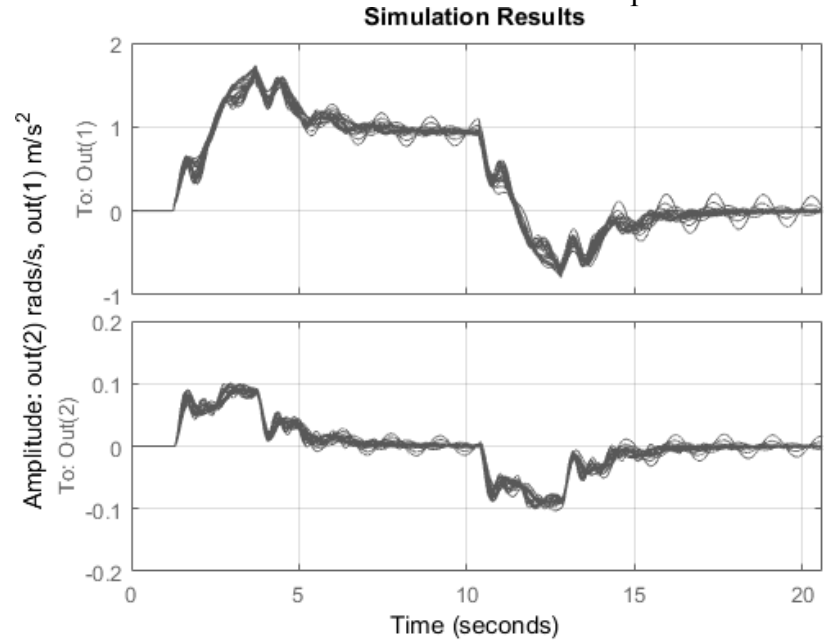

Fig.13. Lateral acceleration (top) and body gyro (bottom) deterministic track simulations (uncertainty).

The PID control design suggestions here can be considered for active suspensions of similar nature. The authors are currently looking into validation of the proposed scheme as part of an integrated control design framework to other types of tilting platform related systems.

The paper should be of considerable interest to control practicioners, in active suspensions, who may be more familiar with traditional PID control and simple tuning rules.

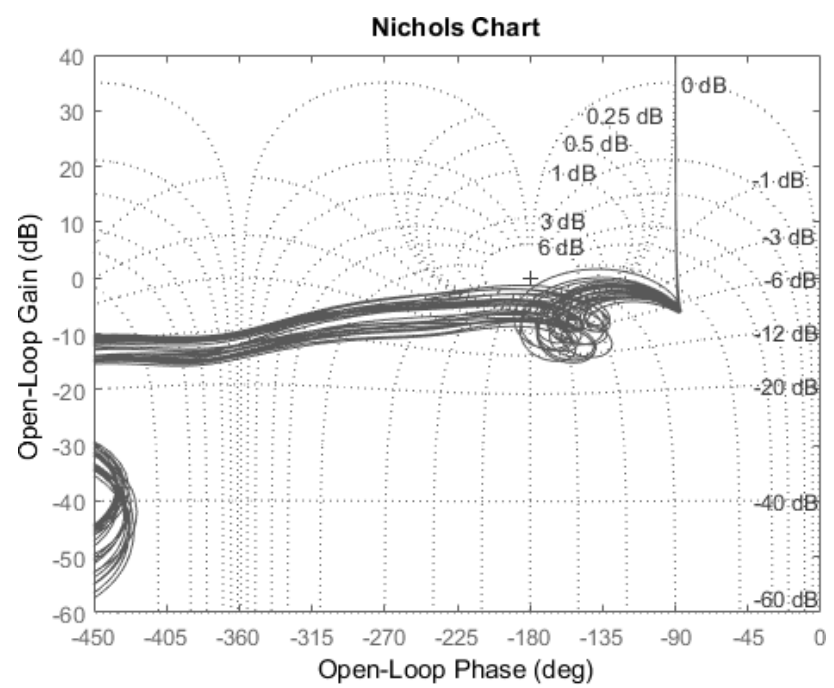

Fig.14. Compensated OL Nichols plot for all uncertain cases (incl nominal).

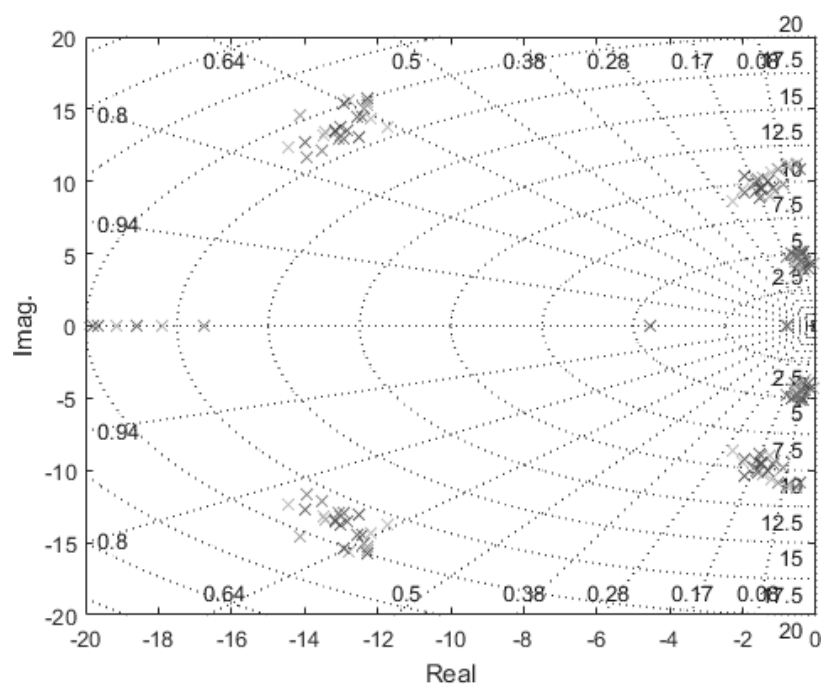

Fig. 15. Pole map of the plant family ( 25 plants; only the poles with real part $>-20$ are shown)

For a discussion on further advanced loop shaping approaches for the current tilt suspension problem, interested readers can can refer to [16], [17].

\section{Acknowledgments}

The first author acknowledges Majlis Amanah Rakyat (MARA) Malaysia for supporting the doctoral studies under $\mathrm{PhD}$ scholarship ref. 330407137000 .

This is an Open Access article distributed under the terms of the Creative Commons Attribution Licence

\section{References}

1. S. Iwnicki, Handbook of railway vehicle dynamics. CRC press, 2006.
2. R. Rajamani, J. Gohl, L. Alexander, and P. Starr, "Dynamics of narrow tilting vehicles," Math. Comput. Model. Dyn. Syst., vol. 9, no. 2 , pp. $209-231,2003$ 
3. K. J. Åström, \& T. Hägglund. Advanced PID Control. Research Triangle Park, NC: ISA- The Instrumentation, Systems, and Automation Society, 2006.

4. Quevedo,J., \& Escobet,T. Digital control: Past,present and future of PID control. Elsevier Science Inc., 2000.

5. Rocco, P. Stability of PID control for industrial robot arms. IEEE Trans. on Robotics \& Autom., 12(4), 606-614, 1996

6. R. Vickerman, "High-speed rail in Europe: experience and issues for future development," Ann. Reg. Sci., vol. 31, no. 1, pp. 21-38, 1997.

7. O. Fröidh, "Perspectives for a future high-speed train in the Swedish domestic travel market," J. Transp. Geogr., vol. 16, no. 4, pp. 268277, 2008.

8. R. Persson, R. M. Goodall, and K. Sasaki, "Carbody tiltingtechnologies and benefits," Veh. Syst. Dyn., vol. 47, no. 8, pp. 949 981, 2009.

9. A. C. Zolotas, G. D. Halikias, and R. M. Goodall, "A Comparison of Tilt Control Approaches for High Speed Railway Vehicles," Proc. 14th Int. Conf. Syst. Eng. (ICSE), Coventry (UK), pp.632636, 2000.

10. J. T. Pearson, R. M. Goodall, and I. Pratt, "Control system studies of an active anti-roll bar tilt system for railway vehicles," Proc. Inst. Mech. Eng. Part F J. Rail Rapid Transit, vol. 212, no. 1, pp. 43-60, 1998.

11. B. H. Huber, "The bogie-based tilt option-simplicity and flexibility," Proc. Inst. Mech. Eng. Part F J. Rail Rapid Transit, vol. 212, no. 1, pp. 19-32, 1998.

12. H. Zamzuri, A. C. Zolotas, and R. M. Goodall, "Tilt control design for high-speed trains: a study on multi-objective tuning approaches," Veh. Syst. Dyn., vol. 46, no. sup1, pp. 535-547, Sep. 2008.

13. H. Zamzuri, A. Zolotas, and R. Goodall, "Optimised intelligent tilt controller scheme using genetic algorithms," presented at the UKACC International Control Conference, Glasgow, UK, 2006.

\section{Appendix A. Variables and Parameters}

$y_{v}, y_{b}, y_{o} \quad$ Lateral displacement of body,bogie and track

$\theta_{v}, \theta_{v}, \delta_{a} \quad$ Roll displacement of body,bogie and

$\theta_{o, n} R \quad$ Track cant, curve radius

$\theta_{r} \quad$ Airspring reservoir roll deflection

$v \quad$ Vehicle forward speed (tilt: $58 \mathrm{~m} / \mathrm{s}$ )

$m_{v} \quad$ Half body mass, $19000(\mathrm{~kg})$

$i_{v r} \quad$ Half body inertia, 25000(kgm)

$m_{b} \quad$ Bogie mass, $2500(\mathrm{~kg})$

$i_{b r} \quad$ Bogie roll inertia, $1500\left(\mathrm{kgm}^{2}\right)$

$k_{a z} \quad$ Airspring area stiffness, $210 \mathrm{e} 3 \mathrm{~N} / \mathrm{m}$

$k_{s z} \quad$ Airspr. series stiffness, $620 \mathrm{e} 3 \mathrm{~N} / \mathrm{m}$

$k_{r z} \quad$ Airspr reservoir. stiffness, 244e $3 \mathrm{~N} / \mathrm{m}$

$c_{r z} \quad$ Airspr. reserv. damping, $33 \mathrm{e} 3 \mathrm{Ns} / \mathrm{m}$

$k_{s y} \quad$ Secondary lateral stiffness, $260 \mathrm{e} 3 \mathrm{~N} / \mathrm{m}$

$c_{s y} \quad$ Secondary lateral damping,33e 3

$\mathrm{Ns} / \mathrm{m}$

$y_{w} \quad$ Bogie kinematic

Appendix B. $\mathbf{P}_{\mathrm{CT}}$ Factor

Pct factor formulae [23]

$$
P_{c t}=(A \ddot{y}+B \dddot{y}-C)_{\geq 0}+D \dot{\theta}^{E}
$$

With the constants given below:

\begin{tabular}{|l|c|c|c|c|c|}
\hline Condition & $A$ & $B$ & $C$ & $D$ & $E$ \\
\hline Standing passengers & 2.80 & 2.03 & 11.1 & 0.185 & 2.283 \\
\hline Seated passengers & 0.88 & 0.95 & 5.9 & 0.120 & 1.626 \\
\hline
\end{tabular}

\section{With:}

$\mathrm{P}_{\mathrm{CT}}=$ passenger comfort index on curve transition, representing the percentage of passengers feeling discomfort $\ddot{y}=$ maximum vehicle body lateral acceleration, in the time interval: beginning of the curve transition and $1.6 \mathrm{sec}$ after the end of the transition (expressed in \%'age of $\mathrm{g}$ ), $\mathrm{g}$ denotes gravity
14. A. C. Zolotas, R. M. Goodall, and G. D. Halikias, "New control strategies for tilting trains," Veh. Syst. Dyn., vol. 37, pp. 171-182, 2002.

15. A. C. Zolotas, J. Wang, and R. M. Goodall, "Reduced-order robust tilt control design for high-speed railway vehicles," Veh. Syst. Dyn., vol. 46, no. S1, pp. 995-1011, 2008.

16. F. Hassan, A. C. Zolotas, R. M. Margetts, "Optimised PID control for tilting trains", Systems Science \& Control Engineering, vol. 5, iss. 1, 2017.

17. F. Hassan, A. Zolotas, R. Margetts, "Improved PID control for tilting trains", 2016 Int'l Conference for Students on Applied Engineering (ICSAE), Newcastle upon Tyne, UK. 2016, pp. 269274. doi: 10.1109/ICSAE.2016.7810201

18. K. J. Åström and T. Hägglund, "Revisiting the Ziegler-Nichols step response method for PID control," J. Process Control, vol. 14, no. 6, pp. 635-650, Sep. 2004.

19. M. Hypiusová, and S. Kajan. "PID controller design by modified Ziegler-Nichols method." Technical Computing Prague 2013: 113.

20. J.J. Gude, \& E. Kahoraho. "Modified Ziegler-Nichols method for fractional PI controllers." Emerging Technologies \& Factory Automation (ETFA), 2010 IEEE Conference on., 2010.

21. M. Graa, M. Nejlaoui, A. Houidi, Z. Affi, \& L. Romdhane. "Mechatronic Rail Vehicle Design Based on the Passenger Comfort.", Journal of Eng. Science \& Tech. Review,9(3), 176-186.

22. J. Förstberg, "Ride comfort and motion sickness in tilting trains," TRITA-FKT Rep., vol. 2000, p. 28, 2000.

23. R. M. Goodall, A. C. Zolotas, and J. Evans, "Assessment of the performance of tilt system controllers," in Proceedings of the Railway Technology Conference IMechE. C, 2000, vol. 580, pp. 231-239.

24. S. Skogestad and I. Postlethwaite, Multivariable feedback control: analysis and design, vol. 2. Wiley New York, 2007.

$\dddot{y}=$ maximum lateral jerk level, calculated as the maximum difference between two subsequent values of $\ddot{y}$ no closer than $1 \mathrm{sec}$, in the time interval: $1 \mathrm{sec}$ before the start of the curve transition and the end of the transition (expressed in $\%$ 'age of $\mathrm{g} / \mathrm{sec}^{\circ}$

$\dot{\theta}=$ maximum absolute value of vehicle body roll speed, in the time interval between the beginning of the curve transition to the end of the curve transition (expressed in degrees per second), dot denotes the derivative with respect to time $\mathrm{t}$
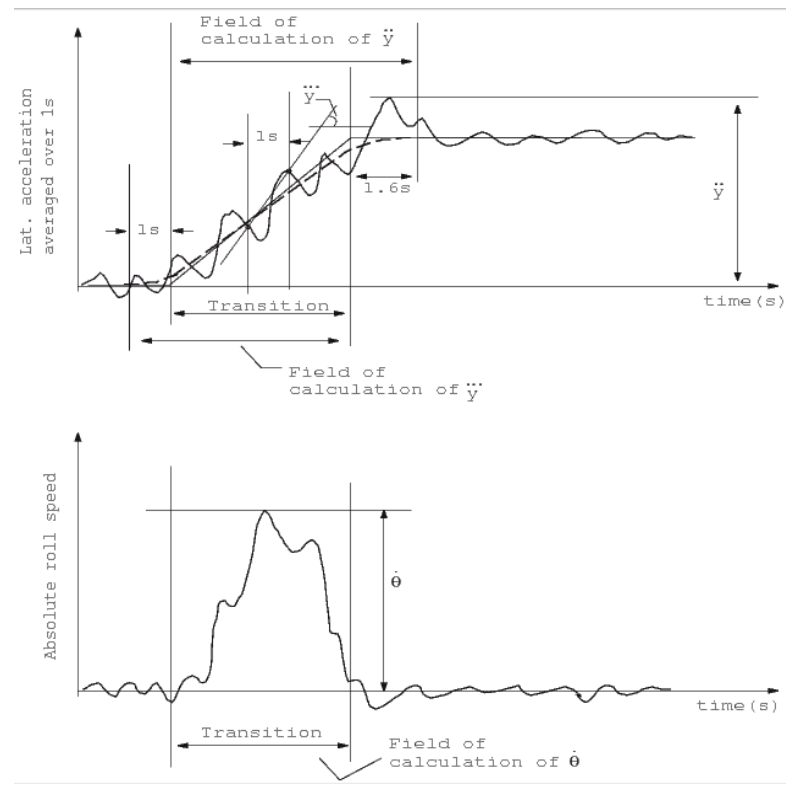

Fig. B.1. $\mathrm{P}_{\mathrm{CT}}$ calculations graphical representation 